\title{
Research on the Heat Dissipation Characteristics of Lithium Battery Spatial Layout in an AUV
}

\author{
Zhaoyong Mao and Shaokun Yan \\ School of Marine Science and Technology, Northwestern Polytechnical University, Xian 710072, China \\ Correspondence should be addressed to Zhaoyong Mao; maozhaoyong@nwpu.edu.cn
}

Received 8 December 2015; Accepted 7 March 2016

Academic Editor: Aihua Li

Copyright (c) 2016 Z. Mao and S. Yan. This is an open access article distributed under the Creative Commons Attribution License, which permits unrestricted use, distribution, and reproduction in any medium, provided the original work is properly cited.

\begin{abstract}
To meet the power demand requirements of autonomous underwater vehicles (AUVs), the power supply is generally composed of a large number of high-energy lithium battery groups. The lithium battery heat dissipation properties not only affect the underwater vehicle performance but also bring some security risks. Based on the widespread application of lithium batteries, lithium batteries in an AUV are taken as an example to investigate the heat dissipation characteristics of the lithium battery spatial layout in an AUV. With the aim of increasing the safety of lithium batteries, a model is developed for the heat transfer process based on the energy conservation equation, and the battery heat dissipation characteristics of the spatial layout are analyzed. The results indicate that the most suitable distance between the cells and the cross arrangement is better than the sequence arrangement in terms of cooling characteristics. The temperature gradient and the temperature change inside the cabin with time are primarily affected by the navigation speed, but they have little relationship with the environmental temperature.
\end{abstract}

\section{Introduction}

As autonomous underwater vehicles (AUVs) are developing toward the direction of long ranges and high speeds, increasingly more power is urgently needed to support navigation. Because electrochemical reactions occurring within lithiumion batteries will generate heat, the battery compartment of autonomous underwater vehicles works for a long time on large-scale integrated lithium-ion battery packs in a confined space, and thus security and reliability problems will exist. In [1], the heat can be divided into two parts. On the one hand, heat accumulation occurs in the battery cabin because the heat from the battery pack cannot dissipate in a timely manner. On the other hand, the battery pack radiating heat unevenly will cause a local temperature difference, which results in uneven performance between the batteries and ultimately affects the overall performance of the batteries.

At present, domestic and foreign scholars have been focusing on the security problem of AUVs using a lithium battery group to conduct related studies. In [2-7], a study on the control strategy of the lithium battery thermal balance and thermal control system that was designed for the inconsistent influence of the battery power service life was performed. In [8-10], the fluid-solid coupled heat transfer method was used to establish a mathematical physical model of the AUV battery cabin interior heat conduction process with respect to the AUV battery cooling problem. Moreover, the battery discharge current and battery frame thermal conductivity of navigation devices were also analyzed in [11], in which the finite element analysis software ANSYS was used to analyze the lithium battery group temperature field of AUVs and discuss the impacts of different discharge time and boundary conditions on the battery temperature field. In [12], AUV battery cabin steady-state thermal modeling analysis was performed according to the heat transfer process of the key point passive thermal control design of the structure. For the battery thermal aspects in research works, the main focus is in the field of electric power for new energy vehicles. In [13], a model of a large-scale battery pack was established for investigating battery pack heat dissipation; it primarily concentrated on the field of electric power for new energy vehicles. In $[14,15]$, a model for predicting the performance of lithium batteries was established for electric vehicles, and the effect of different groups on the performance of the battery was analyzed in the same cooling mode with 9 single-cell batteries as the battery pack. In addition, 
using forced air cooling and phase-change materials, the cooling performance of the power car battery pack was analyzed based on the computational fluid dynamics method in $[16,17]$. An appropriate battery model is necessary for the proper design and operation of battery systems using BMS. Several modeling approaches are available: empirical models, statistical models, and electrical models [18, 19]. In [20], the local heat generation in a single-stack lithium-ion battery cell was investigated as a function of the $C$-rate and state of charge (SOC). In [21], a combined model was used to study heat generation and heat dissipation as well as their influences on the temperatures of the battery pack with and without a fan under constant current discharge and variable current discharge based on electric vehicle (EV) driving cycles.

The existing studies primarily focus on battery thermal balance control system design. Regarding investigations of the AUV battery cooling layout, analyses have been performed only for navigation within the battery compartment temperature field, but little connections exist with structural layout studies on the thermal performance of the battery pack. In addition, compared to electric power vehicles, the battery cabin of AUVs is a closed compact space, and the use of common cooling methods, such as cold wind and solvent cooling, is limited. The battery pack heat conduction can only be achieved through the battery shell body and seawater, and physical problems involved are how to realize battery cooling through air flow engendered by local temperature variations inside the battery cabin and the heat conduction structure.

The main contribution of this paper is twofold: (i) we analyze the heat exchange process of the vehicle battery pack and establish the natural convection and heat transfer model for the confined space of the battery compartment and (ii) we investigate the heat transfer characteristics of lithium batteries in different spatial distributions.

\section{Modeling of the AUV Lithium Battery Space with External Cooling}

According to the internal structure of the AUV battery cabin and theoretical knowledge of heat transfer, the heat transferred from the battery to the outside seawater can be summarized as the following three aspects of heat conduction. The first part of the heat conduction includes the heat generated by the battery pack and the heat exchange process between the battery cabin and the housing wall. The second part of the heat conduction process is between the cabin housing wall and the outer wall of the housing. Finally, the third part of the heat conduction is battery heat exchange between the outer wall of the cabin housing and seawater. The procedure is shown in Figure 1.

To facilitate analysis of the temperature distribution in the battery cabin under different working conditions, the heat transfer process in the battery cabin was hypothesized and simplified as follows:

(1) The ends of the battery cabin and inner battery pack are insulated.

(2) The temperature distributions inside the battery cabin and battery pack only change in the radial direction

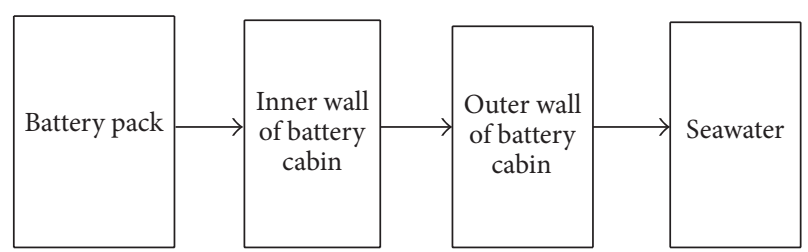

FIGURE 1: Schematic diagram of heat dissipation and conduction of battery cabin.

and remain essentially unchanged in the axial direction.

(3) When the battery cabin works, the thermal parameters do not change over time.

Based on the above analysis, the heat dissipation model of the confined space of the battery cabin is equivalent to the problems of constant properties, inner heat source, and threedimensional unsteady heat transfer.

2.1. Battery inside the Module Heat Analysis. The internal heat transfer process in a lithium battery can be simplified into a regular physical, three-dimensional unsteady heat transfer process within the heat source. For this reason, the internal lithium/thionyl chloride battery energy equation can be expressed as

$$
\begin{gathered}
\mathrm{Bi}=\frac{r_{b} h_{b}}{\lambda_{b}}, \\
\lambda_{b} \frac{\partial^{2} t}{\partial r^{2}}+\frac{\lambda_{b}}{r} \frac{\partial t}{\partial r}+\dot{Q}_{b}=\rho_{b} c_{p b} \frac{\partial t}{\partial \tau} .
\end{gathered}
$$

Boundary conditions are

$$
\begin{aligned}
\tau & =0, \\
t & =T_{w}, \\
r & =0, \\
\frac{\partial t}{\partial r} & =0, \\
r & =r_{b}, \\
-\lambda_{b} \frac{\partial t}{\partial r} & =h_{a}\left(t-t_{a}\right),
\end{aligned}
$$

where $\dot{Q}_{b}$ is the heat generation rate in the overall battery $\left(\mathrm{W} / \mathrm{m}^{3}\right), \lambda_{b}$ is the thermal conductivity of the battery $(\mathrm{W} /(\mathrm{m} \cdot \mathrm{k})), \rho_{b}$ is density of the battery $\left(\mathrm{kg} / \mathrm{m}^{3}\right), \mathrm{Bi}$ is the Biot number, $c_{p b}$ is the specific heat capacity of the battery $(\mathrm{J} /(\mathrm{kg} \cdot \mathrm{K}))$, and $r_{b}$ is the diameter of the battery $(\mathrm{m})$.

When the Biot number of the battery is less than 0.1 under the natural convection environment, the internal temperature of the battery can be considered to be approximately evenly distributed. According to the Bernardi hypothesis, the heat 
generation rate in a single battery is constant, which can be approximately expressed as follows:

$$
Q=\frac{I_{b}}{V_{b}}\left(E_{\mathrm{oc}}-E-t \frac{\partial t}{\partial r}\right) \approx \frac{I_{b}^{2} R_{b}}{V_{b}},
$$

where $V_{b}$ is the volume of the single battery $\left(\mathrm{m}^{3}\right), E_{\text {oc }}$ is the open circuit voltage of the battery (V), $E$ is the discharge voltage of the battery, $R_{b}$ is the internal resistance of the battery $(\Omega), r_{b}$ is the radius of the battery $(\mathrm{m})$, and $I_{b}$ is the current of the single battery.

The heat convection of single cells occurs primarily through air convection and radiative heat transfer according to the ideal gas equation:

$$
P v=\frac{m R t_{a}}{M_{a}}
$$

The air density is

$$
\rho_{a}=\frac{M_{a} p}{R t_{a}} .
$$

As shown by the above equation, a change in temperature can cause a change in air density in the battery cabin, and natural convection forms under the effect of gravity. Ignoring the effects of volume force and viscous force, the momentum conservation equation of air in the battery cabin can be expressed as follows:

$$
\begin{aligned}
& \frac{\partial\left(\rho_{a} u\right)}{\partial \tau}+\operatorname{div}\left(\rho_{a} u \vec{v}\right)=\operatorname{div}\left(\eta_{a} \operatorname{grad} u\right)-\frac{\partial p}{\partial x}, \\
& \frac{\partial\left(\rho_{a} v\right)}{\partial \tau}+\operatorname{div}\left(\rho_{a} v \vec{v}\right)=\operatorname{div}\left(\eta_{a} \operatorname{grad} v\right)-\frac{\partial p}{\partial y}-\rho_{a} g,
\end{aligned}
$$

where $\eta_{a}$ is the kinematic viscosity of air (Pa.s), $g$ is gravitational acceleration $\left(9.8 \mathrm{~m} / \mathrm{s}^{2}\right), \mathrm{Ma}$ is the molar mass of air, $P$ is air pressure $(\mathrm{Pa})$, and $t_{a}$ is air temperature $(\mathrm{K})$.

The integral equation of the conservation of energy in the form of the cabin battery operation equation can be expressed as follows:

$$
\begin{aligned}
& Q=Q_{\text {out }}+Q_{\text {uns }}, \\
& Q=\int_{V_{b}} Q_{b} d V,
\end{aligned}
$$

where $Q$ is the total heat generated by the battery pack $(J)$, $Q_{\text {out }}$ is the heat dissipating from the battery cabin to the outside $(J)$, and $Q_{u n s}$ is the heat absorbed by the battery cabin (J).

Heat transfers between the battery and vehicle wall primarily through natural air convection, and the heat generated by the battery part dissipates into the environment via the shell. The other part of the heat is absorbed by the shell of the vehicle, which causes the battery cabin temperature to increase. The purpose of this study is aimed at increasing the proportion of $Q_{\text {out }}$ and lowering the proportion
TABLE 1: Parameters of 18650-type battery.

\begin{tabular}{lc}
\hline Parameter & Value \\
\hline Diameter $[\mathrm{m}]$ & 0.018 \\
Length $[\mathrm{m}]$ & 0.065 \\
Weight $[\mathrm{kg}]$ & 0.048 \\
Internal resistance $[\Omega]$ & $0.03-0.06$ \\
Density $\left[\mathrm{kg} \cdot \mathrm{m}^{-3}\right]$ & 2900 \\
Specific heat capacity $\left[\mathrm{J} \cdot \mathrm{kg}^{-1} \cdot \mathrm{K}^{-1}\right]$ & 1000 \\
Equivalent heat conductivity $\left[\mathrm{W} \cdot \mathrm{m}^{-1} \cdot \mathrm{K}^{-1}\right]$ & 3 \\
Nominal voltage $[\mathrm{V}]$ & 3.6 \\
Rated capacity $[\mathrm{Ah}]$ & 2.5 \\
\hline
\end{tabular}

of $Q_{\text {uns }}$, thereby reducing the temperature of the battery module:

$$
\begin{aligned}
Q_{\text {out }} & =\int_{A_{c}} h_{a}\left(t-t_{c i}\right) d S+\int_{A_{k}} h_{w}\left(t-t_{h}\right) d S, \\
Q_{\text {uns }} & =\frac{\partial}{\partial \tau} \int_{V_{b}} \rho_{b} c_{p b} t d V+\frac{\partial}{\partial \tau} \int_{V_{a}} \rho_{a} c_{p a} t d V .
\end{aligned}
$$

Boundary conditions are

$$
\begin{aligned}
\tau & =0, \\
t & =T_{w}, \\
r & =r_{c}, \\
-\lambda_{w} \frac{\partial t}{\partial \tau} & =h_{a}\left(t-t_{c i}\right),
\end{aligned}
$$

where $A_{c}$ is the heat transfer area of the inner wall of the vehicle $\left(\mathrm{m}^{2}\right), V_{a}$ is the volume of air inside the battery cabin $\left(\mathrm{m}^{3}\right), \rho_{a}$ is the air density $\left(\mathrm{kg} / \mathrm{m}^{3}\right), c_{p a}$ is the specific heat capacity of air $(\mathrm{J} /(\mathrm{kg} \cdot \mathrm{K})), \lambda_{w}$ is the heat conductivity of the vehicle housing $(\mathrm{W} /(\mathrm{m} \cdot \mathrm{K})), h_{a}$ is the convective heat transfer coefficient of air in the battery cabin $\left(\mathrm{W} /\left(\mathrm{m}^{2} \cdot \mathrm{k}\right)\right), t_{h}$ is the seawater temperature $\left({ }^{\circ} \mathrm{C}\right)$, and $t_{c i}$ is the initial temperature in the battery compartment $\left({ }^{\circ} \mathrm{C}\right)$.

2.2. Heat Exchange between the Inner and Outer Walls of the Battery Cabin. Heat transfer from the inner wall to the outer wall of the battery cabin can be considered as heat conduction of a cylindrical wall, which can be expressed as follows:

$$
\begin{aligned}
\phi & =A_{c i} k_{c}\left(t_{c i}-t_{c o}\right), \\
t_{c i} & =t_{c o}+\frac{\phi}{A_{c i} k_{c}},
\end{aligned}
$$

where $\phi$ is the total heat through the bulkhead and the water exchange $(\mathrm{J}), A_{c i}$ is the heat transfer area of the inner wall $\left(\mathrm{m}^{2}\right), k_{c}$ is the equivalent heat conductivity of the battery wall $(\mathrm{W} /(\mathrm{m} \cdot \mathrm{k}))$, and $t_{c i}$ is the temperature of the battery inner wall $\left({ }^{\circ} \mathrm{C}\right)$. 

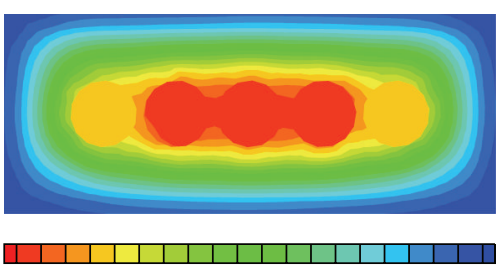
ơ सुm

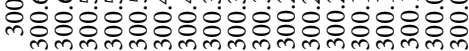

Temperature

(a) $L=0.1 d$

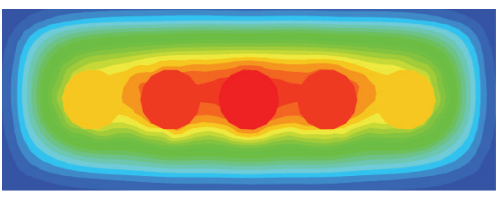

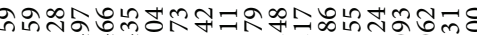

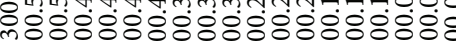

Temperature

(c) $L=0.3 d$
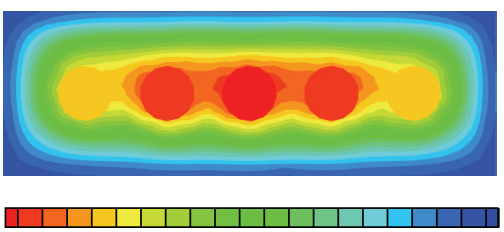

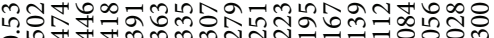

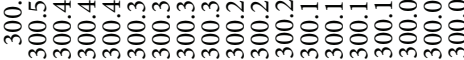

Temperature

(e) $L=0.5 d$

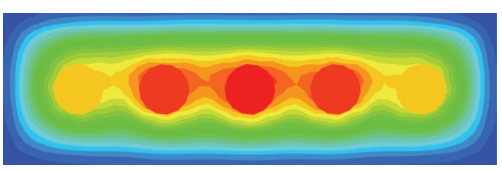

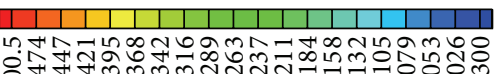

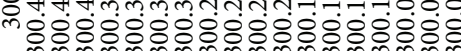

Temperature

(g) $L=0.7 d$

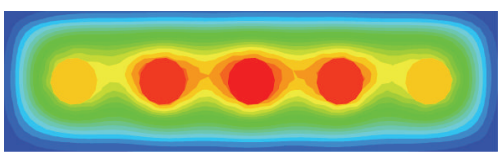

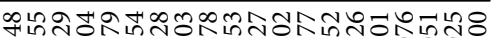

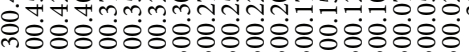

Temperature

(i) $L=0.9 d$

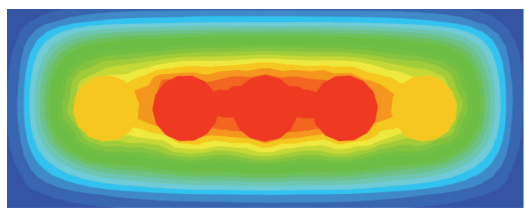

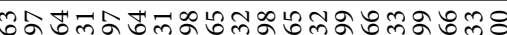

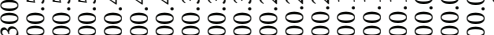

Temperature

(b) $L=0.2 d$

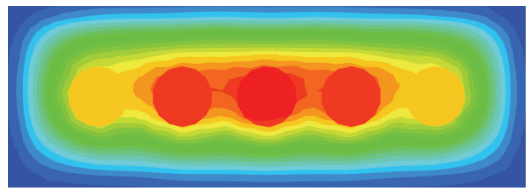

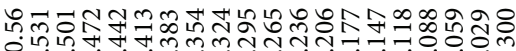
宛

Temperature

(d) $L=0.4 d$

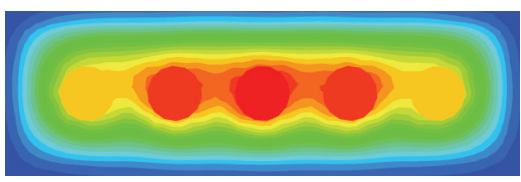

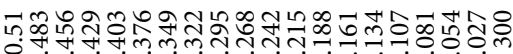

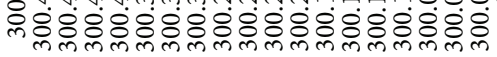
Temperature

(f) $L=0.6 d$

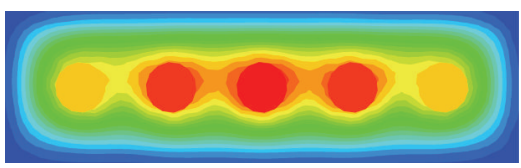

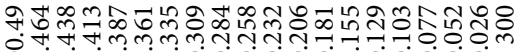

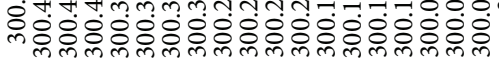
Temperature

(h) $L=0.8 d$
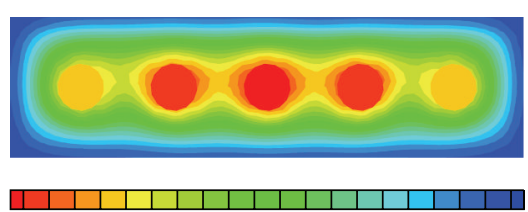

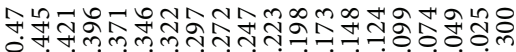
品

Temperature

(j) $L=1.0 d$

Figure 2: Temperature distribution inside the battery compartment under different spacings between cells. 
TABLE 2: Changes in temperature differences with varying cell spacings.

\begin{tabular}{|c|c|c|c|c|c|c|c|c|c|c|}
\hline Cell spacing $(\mathrm{m})$ & $0.1 d$ & $0.2 d$ & $0.3 d$ & $0.4 d$ & $0.5 d$ & $0.6 d$ & $0.7 d$ & $0.8 d$ & $0.9 d$ & $1.0 d$ \\
\hline Temperature difference value $\left({ }^{\circ} \mathrm{C}\right)$ & 0.68 & 0.63 & 0.59 & 0.56 & 0.53 & 0.51 & 0.50 & 0.49 & 0.48 & 0.47 \\
\hline
\end{tabular}

TABLE 3: Certain underwater vehicle dynamic system indicators.

\begin{tabular}{lc}
\hline Parameter & Value \\
\hline Speed & $4 \mathrm{kn}$ \\
Flight & $70 \mathrm{~km}$ \\
Power & $180 \mathrm{~W}$ \\
Operating voltage & $21 \mathrm{~V} \sim 30 \mathrm{~V}$ \\
\hline
\end{tabular}

2.3. Heat Exchange between the Outer Wall of the Vehicle Housing and Seawater. During underwater movement, forced convection heat transfer occurs between the outer wall of the battery cabin and seawater, which can be expressed as follows:

$$
\begin{aligned}
\phi & =A_{c o} h_{c f}\left(t_{c o}-T_{w}\right), \\
A_{c o} & =2 \pi r_{c o} l_{c} \\
t_{c o} & =\frac{\phi}{2 \pi r_{c o} l_{c} h_{c f}}+T_{w},
\end{aligned}
$$

where $\phi$ is the heat exchanged between the battery cabin and seawater (W), $A_{c o}$ is the heat transfer area of the inner wall $\left(\mathrm{m}^{2}\right), r_{c o}$ is the outer diameter of the vehicle housing $(\mathrm{m}), t_{c o}$ is the outer wall temperature $\left({ }^{\circ} \mathrm{C}\right), T_{w}$ is the seawater temperature $\left({ }^{\circ} \mathrm{C}\right)$, and $h_{c f}$ is the forced convection heat transfer coefficient between the outer wall and seawater $\left(\mathrm{W} /\left(\mathrm{m}^{2} \cdot \mathrm{K}\right)\right)$.

The forced convection heat transfer coefficient between the outer wall and seawater is related to the sailing speed, which can be determined by the Reynolds number and Nusselt number of convective heat transfer between the outer wall and seawater:

$$
\begin{aligned}
h_{c f} & =\mathrm{Nu}_{c f} \frac{\lambda_{f}}{l_{c}} \\
\mathrm{Nu}_{c f} & =\left(0.037 \mathrm{Re}^{4 / 5}-871\right) \operatorname{Pr}^{1 / 3}, \\
\operatorname{Re} & =\frac{u_{c f} l_{c}}{v_{f}} .
\end{aligned}
$$

Without consideration of seawater flow,

$$
u_{c f}=v
$$

where $\lambda_{f}$ is the heat conductivity of seawater $(\mathrm{W} /(\mathrm{m} \cdot \mathrm{K}))$, $\mathrm{Nu}_{c f}$ is the Nusselt number of convective heat transfer between the vehicle housing and seawater, Re is the Reynolds number of convective heat transfer between the vehicle housing and seawater, Pr is the Prandtl number of seawater, $v_{f}$ is the kinematic viscosity of seawater $\left(\mathrm{m}^{2} / \mathrm{s}\right), u_{c f}$ is

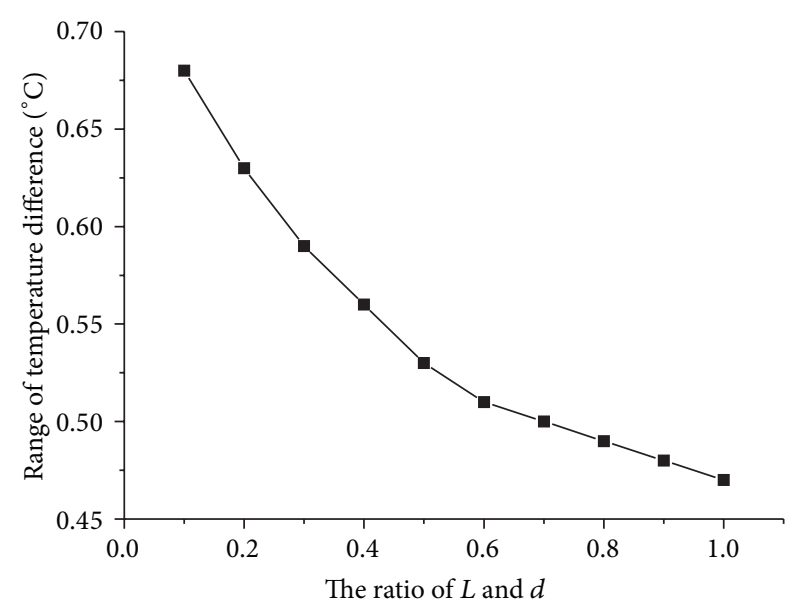

FIGURE 3: Curve of the temperature difference variations with the distance between the batteries.

the relative velocity $(\mathrm{m} / \mathrm{s})$ between seawater and the vehicle, $v$ is the barycentric velocity of the vehicle $(\mathrm{m} / \mathrm{s})$, and $l_{c}$ is the characteristic length of the battery cabin $(\mathrm{m})$.

\section{Analysis of the Influence of Space and Arrangement on the Heat Dissipation Characteristics of the Battery Pack}

Based on the lithium-ion battery pack for underwater space external thermal model and because the AUV battery compartment is a closed and compact space, the distance between batteries and combining types for the distribution of the temperature gradient inside the battery compartment have a great impact. This paper selects a winding-type lithium/thionyl chloride battery named 18650 as an example to analyze cells with different spaces and different permutations. Numerical parameters related to a single 18650 battery are shown in Table 1 .

3.1. Influence of Battery Spacing on Temperature Field of Battery Pack. The domain is described using triangular elements, with a total number of approximately 20,000. Grids closest to the profiles of the batteries were refined with triangular boundary elements to describe the boundary flow with sufficient precision. The distance between two adjacent cells is the same, and the distance between the boundary and batteries remains constant. The distances between the batteries change continually under the premise of shape and constant number of batteries.

With 5 single 18650 batteries as the objects, the space between the batteries $(L)$ is studied. The temperature of the battery compartment is determined when the values of $L$ are 
TABLE 4: Battery performance parameters at different speeds.

\begin{tabular}{lccc}
\hline Speed $/ \mathrm{kn}$ & Single battery current/A & Surface heat transfer coefficient $\left(\mathrm{W} /\left(\mathrm{m}^{2} \cdot \mathrm{K}\right)\right)$ & $\mathrm{Heat}$ rate $\mathrm{Q}\left(\mathrm{W} / \mathrm{m}^{3}\right)$ \\
\hline 4 & 0.27 & 1564 & 172 \\
5 & 0.52 & 2854 & 655 \\
6 & 0.90 & 4094 & 1958 \\
\hline
\end{tabular}
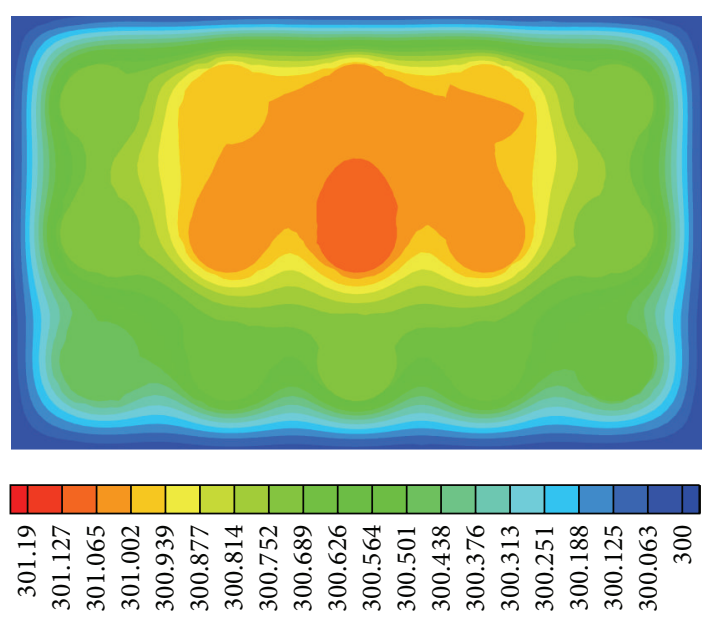

Temperature

(a) Sequential arrangement
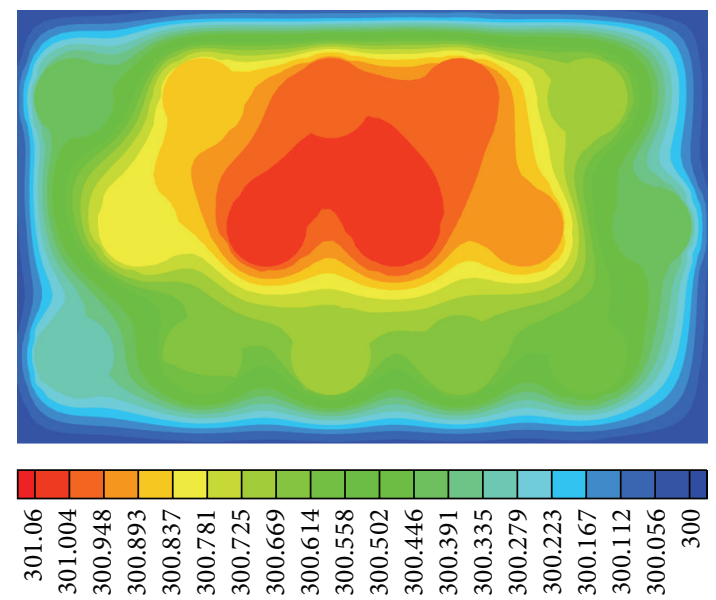

Temperature

(b) Cross arrangement

FIGURE 4: Simulation results of sequential arrangement and cross arrangement.

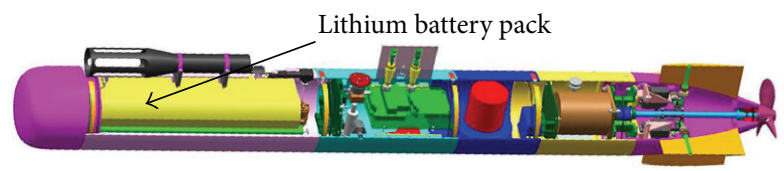

FIgURE 5: Certain structural layout AUV.

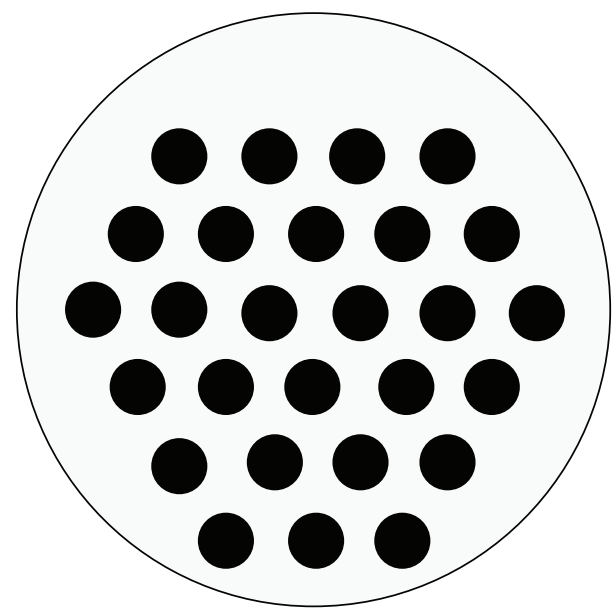

FIGURE 6: Schematic layout of the battery pack.

$0.1 d, 0.2 d, 0.3 d, 0.4 d, 0.5 d, 0.6 d, 0.7 d, 0.8 d, 0.9 d$, and $1.0 d$ (where $d$ is the diameter of the battery). The temperature distributions are shown in Figure 2.

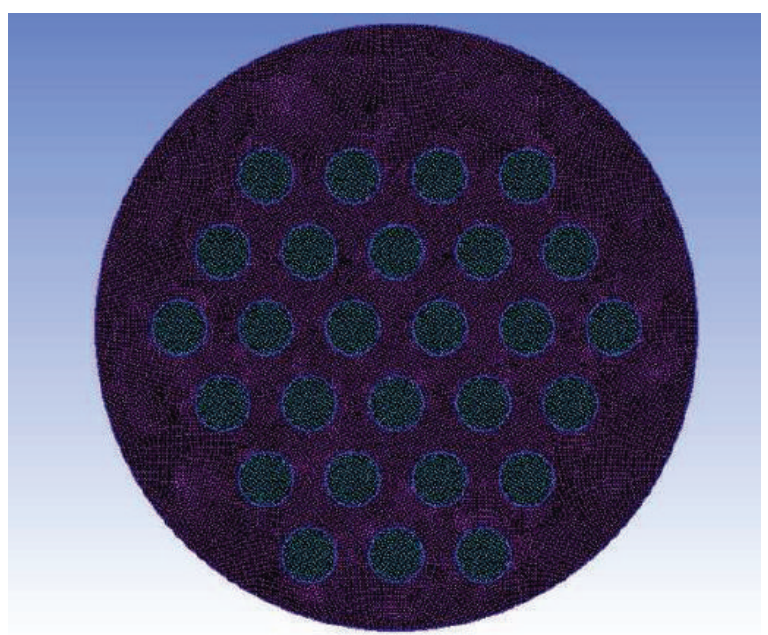

FIGURE 7: Underwater vehicle battery compartment mesh.

Table 2 presents the temperature differences inside the battery compartment when the batteries are located at different distances between cells. The variations in the temperature differences in the battery compartment with varying cell distances are shown in Figure 3.

Table 2 and Figure 3 show that as the distance between the batteries increases, the internal temperature gradient gradually decreases. The temperature change inside the battery compartment is stable, and the temperature decreases $0.01^{\circ} \mathrm{C}$ 

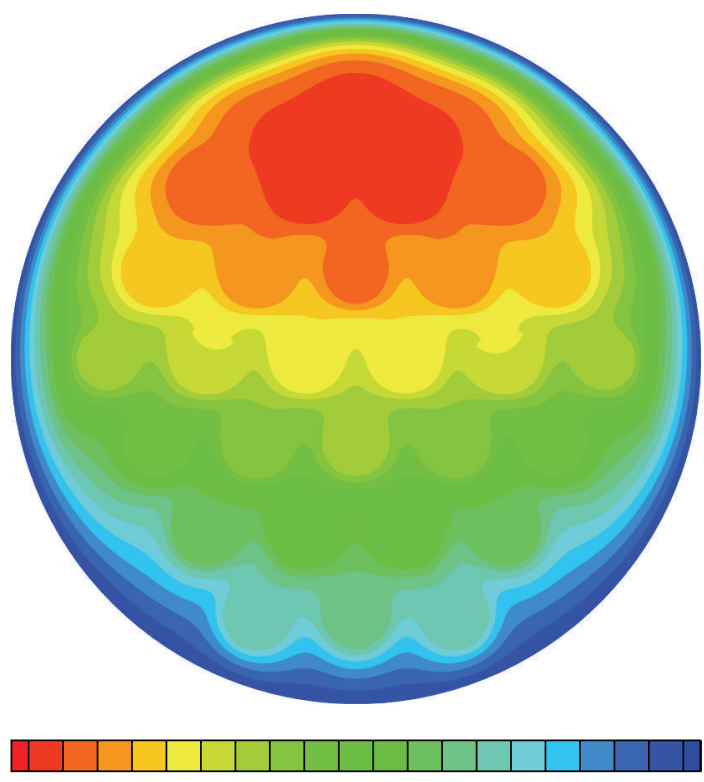

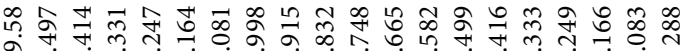
$\infty$
$\sim$
$\sim$ Temperature

(a) Vehicle speed is $4 \mathrm{kn}$

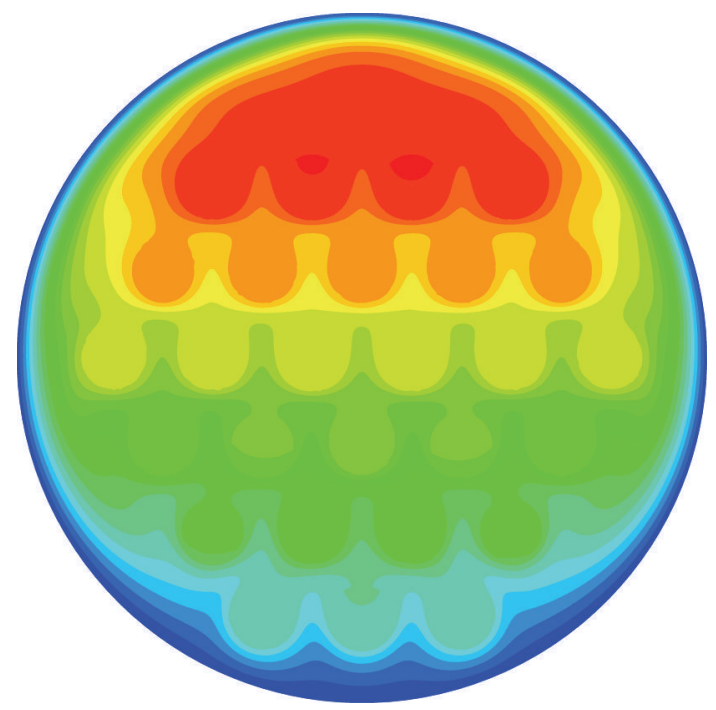

눈 רั Temperature

(b) Vehicle speed is $5 \mathrm{kn}$

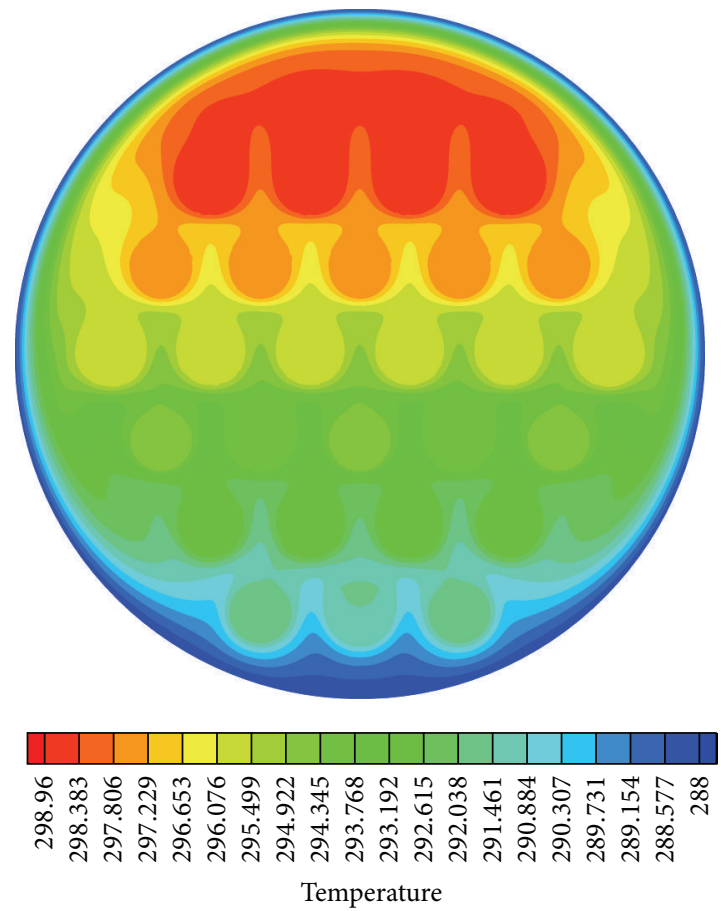

(c) Vehicle speed is $6 \mathrm{kn}$

FIGURE 8: Battery compartment internal temperature profile at different speeds. 


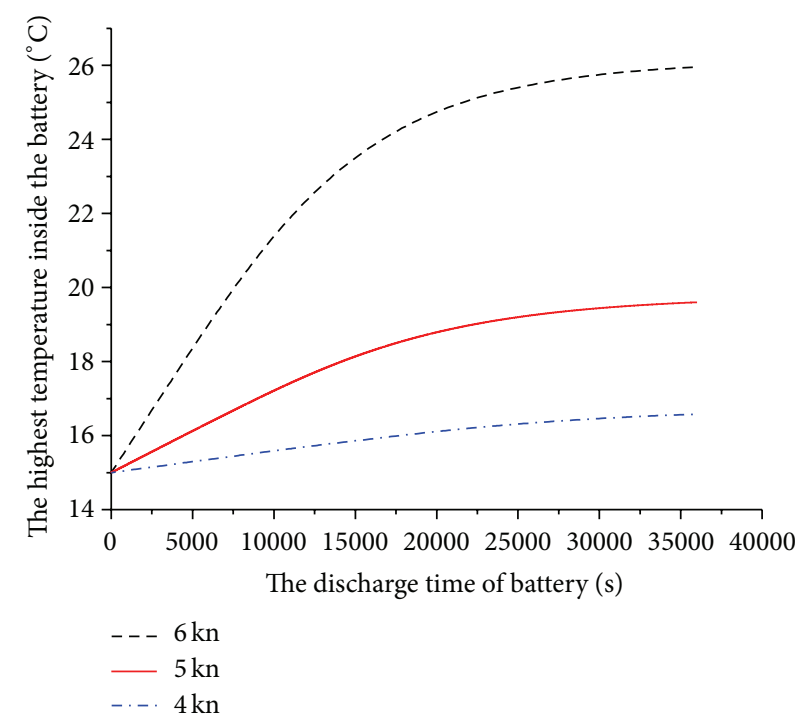

FIGURE 9: The maximum temperature changes over time.

when the distance between batteries increases, $0.1 d$ from $L=0.6 d$. Therefore, the best distance between batteries is $0.6 d$.

3.2. Influence of Battery Arrangement on Temperature Field of Battery Pack. Under the premise of the most suitable distance $(L=0.6 d)$ of the battery inside the model, 15 single 18650 batteries are divided into three parts as objects, in which each is composed of 5 batteries and the distance between the batteries is $0.6 d$. In this paper, we investigate the influence of the sequential arrangement and the cross arrangement of the batteries on the temperature field of the battery pack. The first row and the third row of the battery pack move to the left at $0.3 d$, and the second row moves to the right at $0.3 d$. The temperature field distribution in the battery pack is shown in Figure 4.

Figure 4 shows that the temperature difference between the battery packs is $1.19^{\circ} \mathrm{C}$ when in the sequential arrangement and that the temperature difference between the battery packs is $1.06^{\circ} \mathrm{C}$ when in the cross arrangement. Comparing the two sets of data reveals that the cross arrangement is better than the sequential arrangement in terms of the temperature gradient.

\section{Underwater Vehicle Battery Pack Spatial Layout Thermal Simulation Analysis}

On the basis of the previous discussion, take the batteries that are in the cross arrangement. Additionally, select the distance between batteries as $0.6 d$; the project team developed a certain type of AUV lithium battery for the study (Figure 5). Its battery spatial structure and layout design are studied. Moreover, simulation of the temperature distribution in the battery compartment of an AUV at different speeds and different sea temperature is performed to investigate the effects of vehicle speed and water temperature on the cabin temperature distribution.

4.1. Underwater Vehicle Battery Pack Spatial Structure Layout. Certain underwater vehicle powertrain design specifications are shown in Table 3. According to energy estimates, the power battery requires at least 189 batteries when 18650 lithium/thionyl chloride batteries are used.

The formula for calculating the number of batteries is as follows:

$$
N=\frac{s P}{v V C},
$$

where $N$ is the number of batteries required, $s$ is the flight $(\mathrm{km}), P$ is the power to the AUV (W), $v$ is the speed of the $\operatorname{AUV}(\mathrm{kn}), V$ is the nominal voltage of the 18650 battery $(\mathrm{V})$, and $C$ is the battery-rated capacitance of the 18650 battery (Ah).

The battery pack sets 189 batteries into 7 series groups, with each group including 27 parallel batteries. The battery pack was installed in the battery cabin with a diameter of $200 \mathrm{~mm}$ to provide an operating voltage of 21 to $30 \mathrm{~V}$. See Figure 6 for the structure.

4.2. AUV Lithium Battery Thermal Simulation Analysis. According to the analysis assumptions, the heat dissipation model of the confined space of the battery cabin is equivalent to the problems of constant properties, inner heat source, and two-dimensional unsteady heat transfer. A cross section of the battery cabin was taken as the calculation area, and the preprocessing program of ANSYS was used to construct the finite element analysis model through cell type selection, material parameters decision, geometric modeling, and cell generation.

The domain is described with triangular elements, with a total number of approximately 72,000 . The total number 


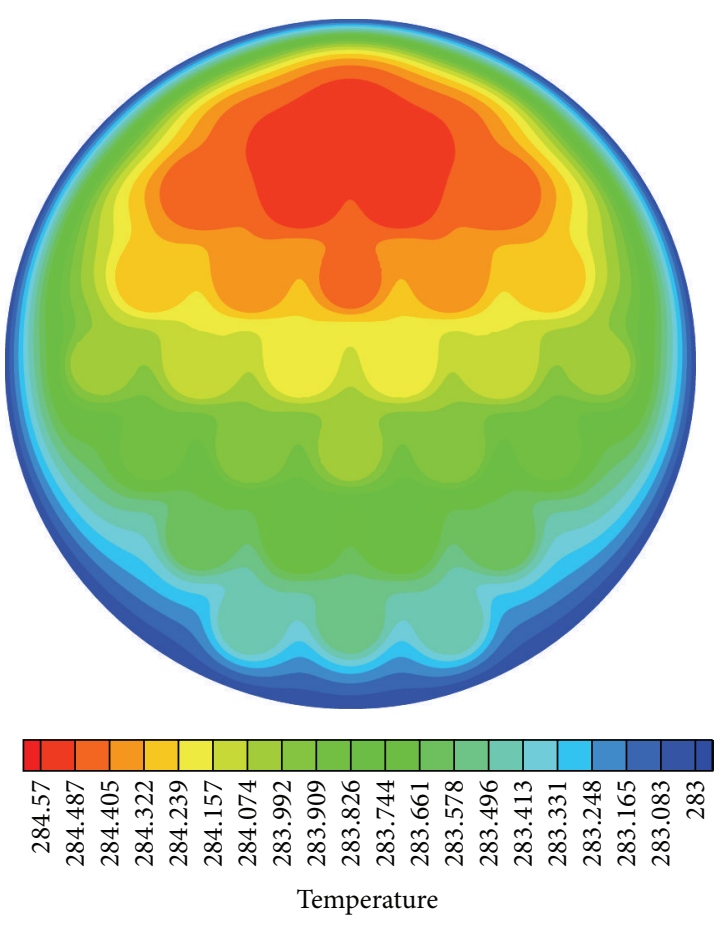

(a) Seawater temperature is $10^{\circ} \mathrm{C}$

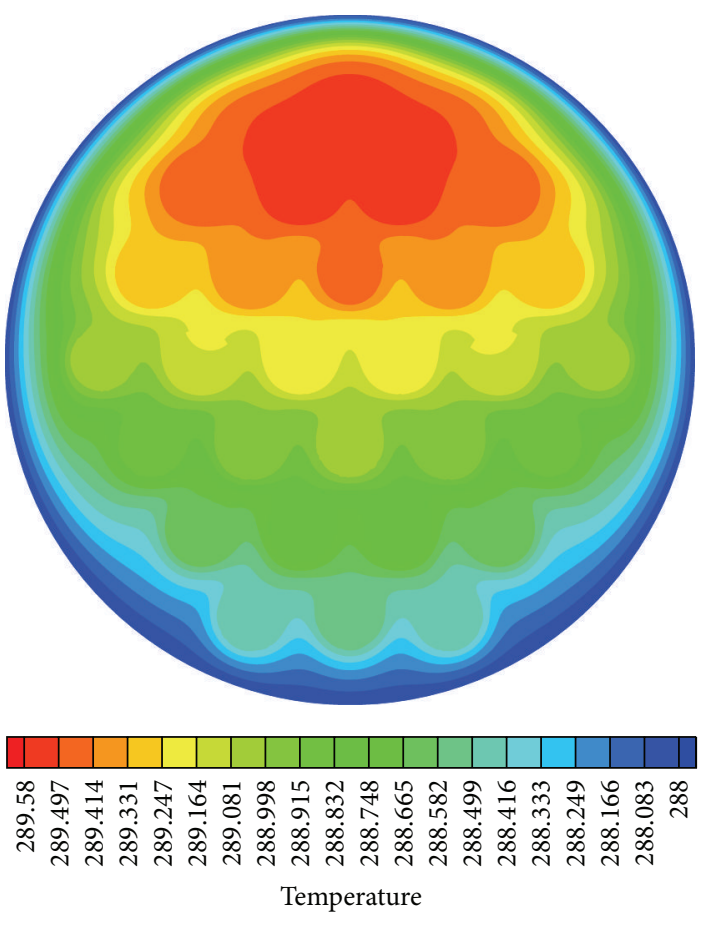

(b) Seawater temperature is $15^{\circ} \mathrm{C}$

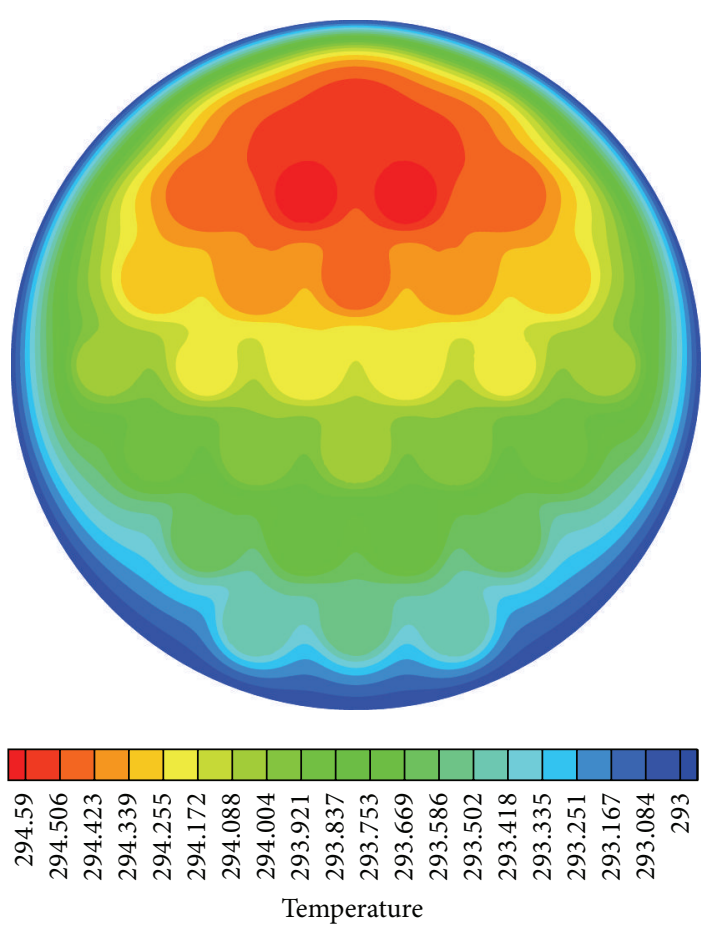

(c) Seawater temperature is $20^{\circ} \mathrm{C}$

FIGURE 10: The battery compartment temperature distribution when the speed is $4 \mathrm{kn}$.

of nodes is approximately 7300 , and some grids closest to the profiles of the batteries and navigation shell were refined with triangular boundary elements to describe the boundary flow with sufficient precision. The grid of the model was divided as shown in Figure 7.
4.2.1. The Effect of Navigating Speed on Temperature inside the Battery Compartment Changing over Time. Batteries for underwater cabins have different heats per unit of time when sailing at different speeds. After analysis, the direction in which the vehicle experiences resistance (the direction of 


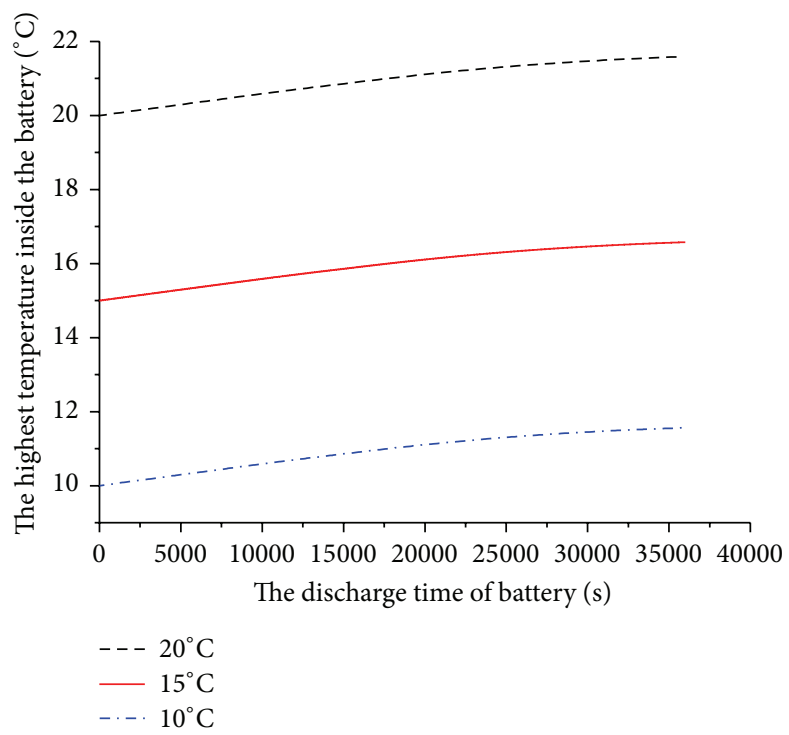

Figure 11: The battery compartment maximum temperatures over time when the speed is $4 \mathrm{kn}$.

the center of gravity speed) is opposite to the direction of navigation. Namely, the speed line is in the opposite direction of the $x$-axis. Dimensionless coefficients can be expressed as

$$
X=c_{x} \frac{1}{2} \rho v^{2} S_{c}
$$

Vehicle power can be expressed as follows:

$$
P=X v=c_{x} \frac{1}{2} \rho S v^{3},
$$

where $X$ is the resistance to the vehicle, $c_{x}$ is the resistance coefficient, $\rho$ is the seawater density, and $S$ is the maximum cross-sectional area of the vehicle.

Therefore, the current through a single battery is

$$
I_{b}=\frac{P_{b}}{E_{b}}=\frac{P}{N \cdot E_{b}}=\frac{c_{x} r S v^{3}}{2 \cdot N \cdot E_{b}}
$$

where $P_{b}$ is the output power of a single battery (W) and $E_{b}$ is its nominal voltage $(\mathrm{V})$. $N$ is the total number of battery cells in the body.

It can be seen that the heat production of a single battery is associated with the vehicle speed. Select vehicle speeds of $4 \mathrm{kn}, 5 \mathrm{kn}$, and $6 \mathrm{kn}$. The performance parameters of batteries at different speeds are shown in Table 4.

After the batteries discharge for 10 hours, the simulation analysis shows that the temperature distribution in the battery cabin is as shown in Figure 4 when the seawater temperature is $15^{\circ} \mathrm{C}$ and the sailing speeds are $4 \mathrm{kn}, 5 \mathrm{kn}$, and $6 \mathrm{kn}$. Moreover, the curve of the change in maximum temperature over time is presented in Figure 8.

After continuous discharging for $10 \mathrm{~h}$, the curve of the maximum temperature of the battery compartment over time is as shown in Figure 9.

As shown in Figures 8 and 9, the seawater temperature is $15^{\circ} \mathrm{C}$ and the discharge time is $10 \mathrm{~h}$. When the sailing speed is $4 \mathrm{kn}$, the temperature difference is $1.58^{\circ} \mathrm{C}$; when the speed is $5 \mathrm{kn}$, the temperature difference is $4.60^{\circ} \mathrm{C}$; and when the speed is $6 \mathrm{kn}$, the temperature difference is $10.96^{\circ} \mathrm{C}$.

Therefore, as the vehicle speed increases, the maximum temperature inside the battery compartment increases and temperature differences increase accordingly. The reasons for this phenomenon are summarized as follows: as the underwater vehicle speed increases, the heat production rate is greater, and more heat is generated per unit time. Because the surface heat transfer coefficient is small, the battery heat generation per unit of time is less than the shell heat distribution per unit of time, resulting in heat concentration and the maximum temperature increasing. In addition, the minimum temperature is always the environmental temperature, which remains unchanged, and the battery compartment temperature increases as the vehicle speed increases.

4.2.2. The Effects of Different Environmental Temperatures on the Battery inside Cabin Temperature versus Time Relationship. For accuracy, select navigation speeds of $4 \mathrm{kn}, 5 \mathrm{kn}$, and $6 \mathrm{kn}$ to study the effects of seawater temperature on the temperature distribution inside the battery cabin when the water temperatures are $10^{\circ} \mathrm{C}, 15^{\circ} \mathrm{C}$, and $20^{\circ} \mathrm{C}$, respectively.

After the batteries continuously discharge for 10 hours, the simulation analysis shows that when the vehicle cruising speed is $4 \mathrm{kn}$, the seawater temperatures are $10^{\circ} \mathrm{C}, 15^{\circ} \mathrm{C}$, and $20^{\circ} \mathrm{C}$, and the battery compartment temperature distribution is shown in Figure 10.

After continuously discharging for $10 \mathrm{~h}$, the battery compartment maximum temperature curve over time is as shown in Figure 11. As shown in Figures 10 and 11, after the underwater vehicle sails at a speed of $4 \mathrm{kn}$ and continuously works for $10 \mathrm{~h}$, the battery compartment internal temperature difference is $1.57^{\circ} \mathrm{C}$ when the water temperature is $10^{\circ} \mathrm{C}$; the battery compartment internal temperature difference is 

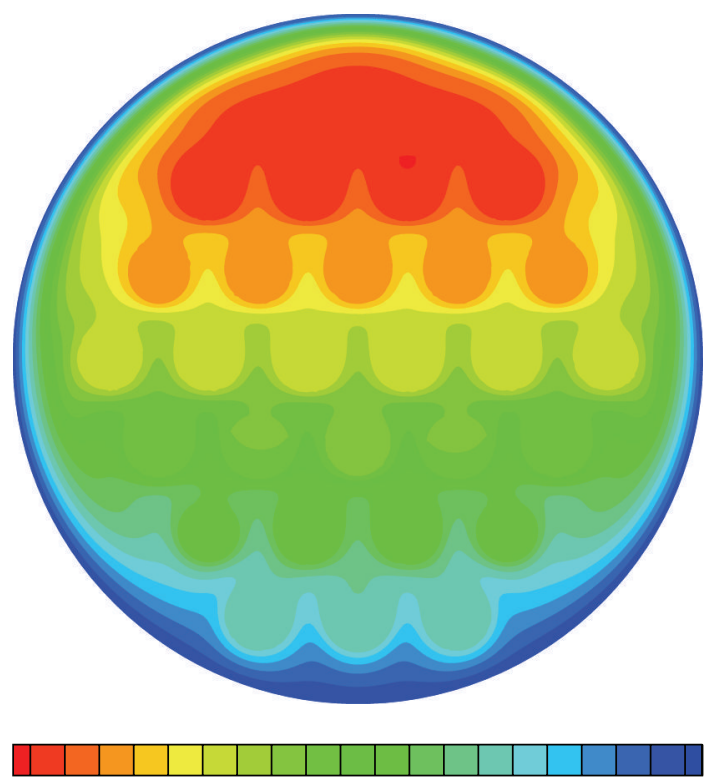

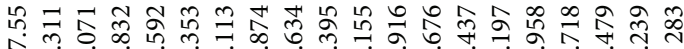

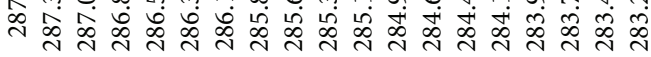
Temperature

(a) Seawater temperature is $10^{\circ} \mathrm{C}$

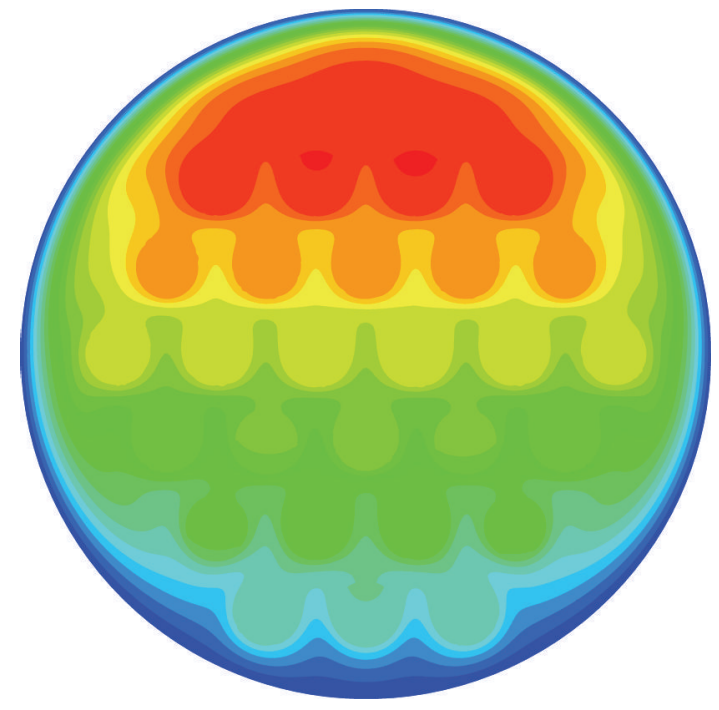

닌

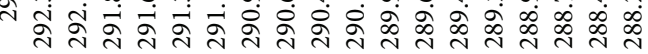
Temperature

(b) Seawater temperature is $15^{\circ} \mathrm{C}$

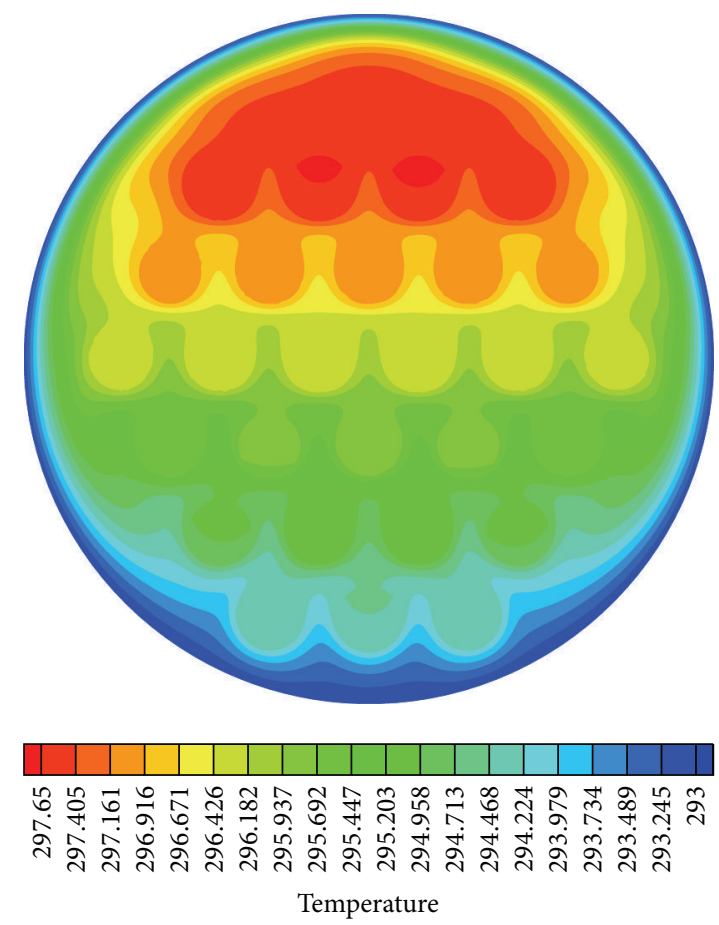

(c) Seawater temperature is $20^{\circ} \mathrm{C}$

FIGURE 12: The battery compartment temperature distribution when the speed is $5 \mathrm{kn}$. 


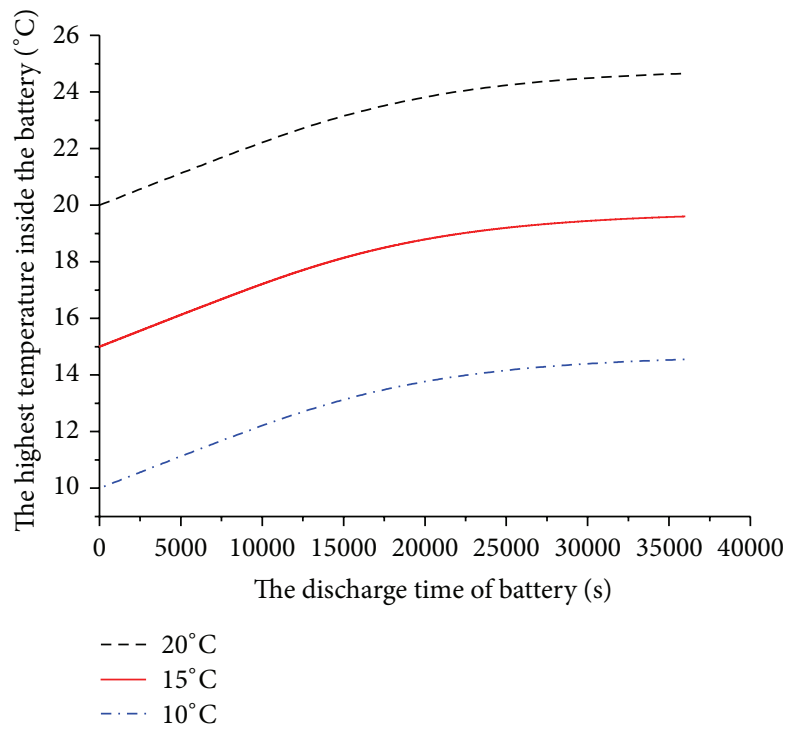

FIgURE 13: The battery compartment maximum temperatures over time when the speed is $5 \mathrm{kn}$.

$1.58^{\circ} \mathrm{C}$ when the water temperature is $15^{\circ} \mathrm{C}$; and the battery compartment internal temperature difference is $1.59^{\circ} \mathrm{C}$ when the water temperature is $20^{\circ} \mathrm{C}$.

After the batteries continuously discharge for 10 hours, the simulation analysis shows that when the vehicle cruising speed is $5 \mathrm{kn}$, the seawater temperatures are $10^{\circ} \mathrm{C}, 15^{\circ} \mathrm{C}$, and $20^{\circ} \mathrm{C}$, and the battery compartment temperature distribution is shown in Figure 12.

After continuously discharging for $10 \mathrm{~h}$, the battery compartment maximum temperature curve over time is as shown in Figure 13. As shown in Figures 12 and 13, after the underwater vehicle sails at a speed of $5 \mathrm{kn}$ and continuously works for $10 \mathrm{~h}$, the battery compartment internal temperature difference is $4.55^{\circ} \mathrm{C}$ when the water temperature is $10^{\circ} \mathrm{C}$; the battery compartment internal temperature difference is $4.60^{\circ} \mathrm{C}$ when the water temperature is $15^{\circ} \mathrm{C}$; and the battery compartment internal temperature difference is $4.65^{\circ} \mathrm{C}$ when the water temperature is $20^{\circ} \mathrm{C}$.

After the batteries continuously discharge for 10 hours, the simulation analysis shows that when the vehicle cruising speed is $6 \mathrm{kn}$, the seawater temperatures are $10^{\circ} \mathrm{C}, 15^{\circ} \mathrm{C}$, and $20^{\circ} \mathrm{C}$, and the battery compartment temperature distribution is shown in Figure 14.

After continuously discharging for $10 \mathrm{~h}$, the maximum temperature inside the battery compartment over time is as shown in Figure 15. As shown in Figures 14 and 15, after the underwater vehicle sails at a speed of $6 \mathrm{kn}$ and continuously works for $10 \mathrm{~h}$, the battery compartment internal temperature difference is $10.84^{\circ} \mathrm{C}$ when the water temperature is $10^{\circ} \mathrm{C}$; the battery compartment internal temperature difference is $10.96^{\circ} \mathrm{C}$ when the water temperature is $15^{\circ} \mathrm{C}$; and the battery compartment internal temperature difference is $11.07^{\circ} \mathrm{C}$ when the water temperature is $20^{\circ} \mathrm{C}$.

To summarize, the water temperature has essentially no effect on the temperature difference inside the battery compartments. The reasons for this phenomenon are summarized as follows: the heat generation rate of batteries within unit time and the forced convection heat transfer coefficient between the outer wall of the vehicle and seawater are unchanged and almost equivalent when the sailing speed is constant. When the seawater temperature increases, the overall temperature in the battery cabin increases, but the temperature difference is basically unchanged.

\section{Conclusion}

In this paper, using theoretical analysis combined with the actual situation and the finite element software ANSYS, we establish the space of lithium batteries for an underwater thermal model. Then, we study the spatial layout of thermal characteristics, and the conclusions are as follows:

(1) A correlation exists between the underwater battery compartment temperature and the distance between the batteries. As the distance between the batteries increases, the temperature gradient gradually changes, and when it reaches a certain threshold, the gradient gradually stabilizes.

(2) Different permutations and combinations between the batteries have effects on the temperature gradient. The cross arrangement is better than the sequential arrangement in terms of the temperature gradient.

(3) The sailing speed affects the change in the temperature gradient and the maximum temperature inside the battery cabin over time. The greater the speed and the battery discharge current, the more the heat that the batteries generate. Then, the temperature increases faster, and less time is required to achieve the steady state. 

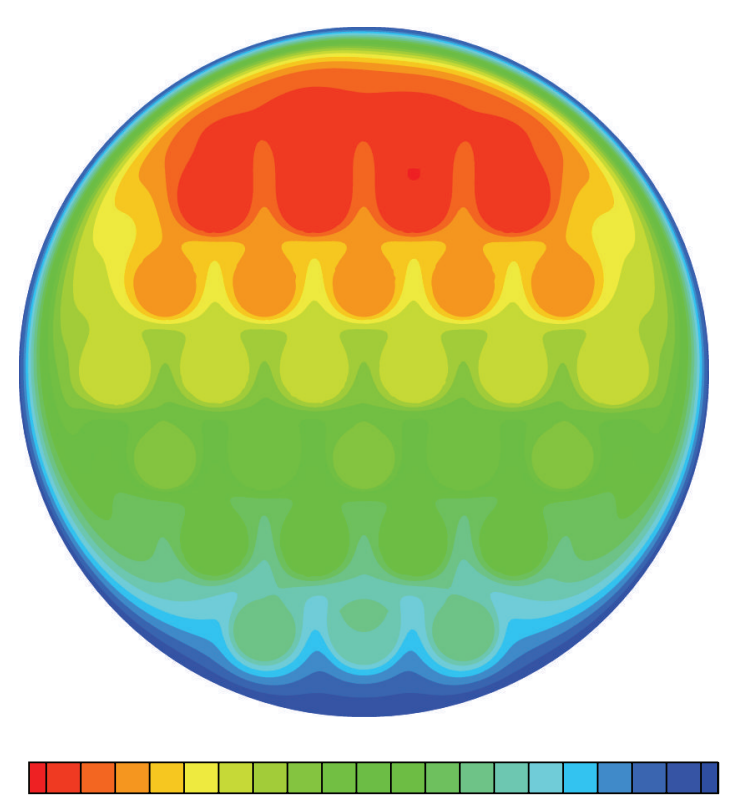

ॠ

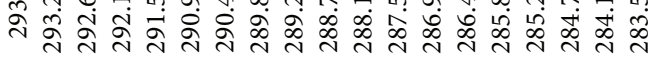
Temperature

(a) Seawater temperature is $10^{\circ} \mathrm{C}$
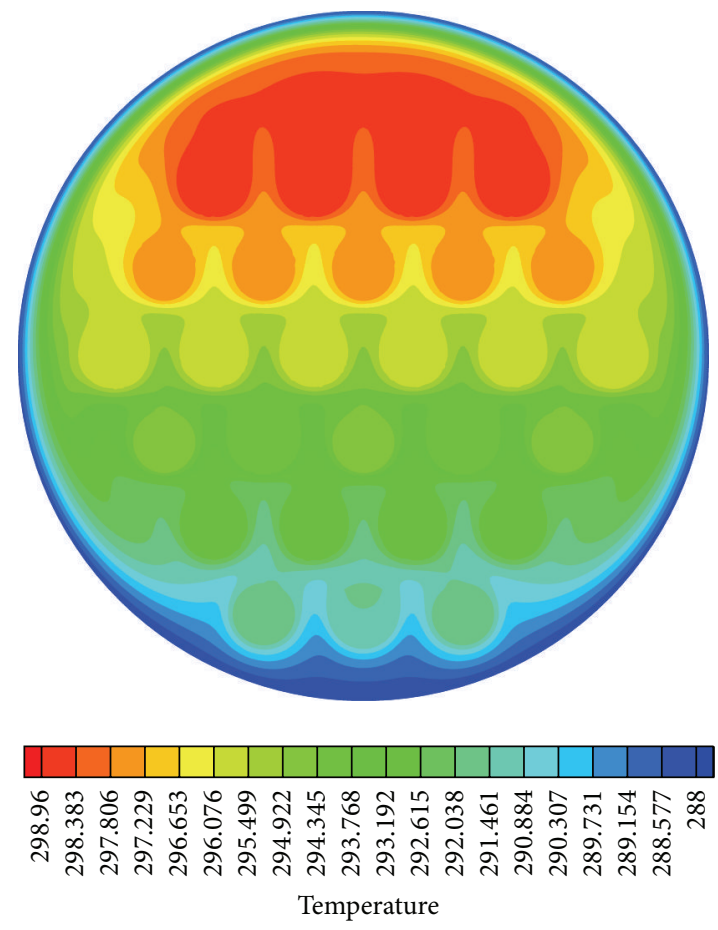

(b) Seawater temperature is $15^{\circ} \mathrm{C}$

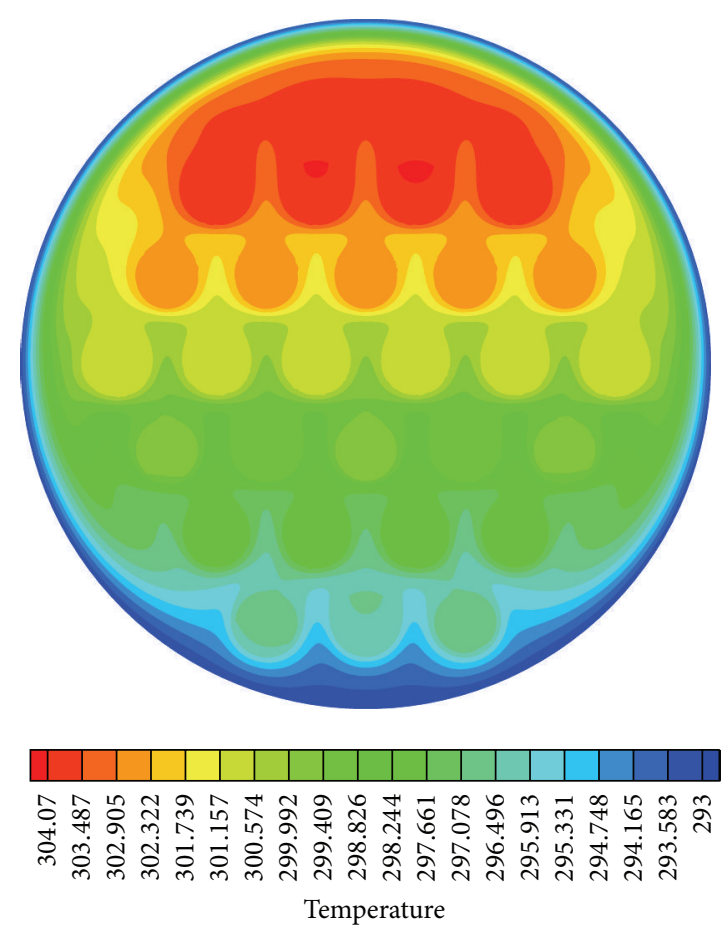

(c) Seawater temperature is $20^{\circ} \mathrm{C}$

FIGURE 14: The battery compartment temperature distribution when the speed is $6 \mathrm{kn}$. 


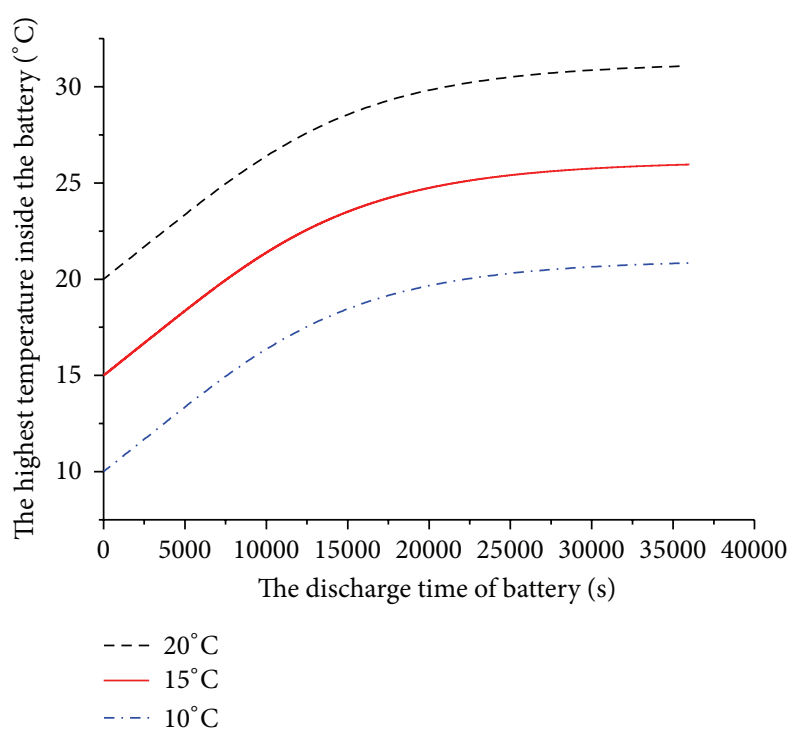

FIGURE 15: The battery compartment maximum temperatures over time when the speed is $6 \mathrm{kn}$.

(4) The seawater temperature rise may cause an overall temperature increase in the battery cabin. However, it has almost no impact on the temperature gradient and uniformity.

\section{Competing Interests}

The authors declare that they have no competing interests.

\section{Acknowledgments}

This work was supported by the National Natural Science Foundation of China (NSFC) under Grant 51509205 and by the Shaanxi Provincial Natural Science Foundation of China 2015JQ5136.

\section{References}

[1] J. Wang and Y. Hu, "Lithium-ion battery temperature field analysis," Power Technology, vol. 32, no. 2, pp. 120-121, 2008.

[2] S. Ogura, I. Kawama, T. Sakurai et al., "Development of oil filled pressure compensated lithium-ion secondary battery for DSV shinkai 6500," in Proceedings of the IEEE MTTS/IEEE TECHNO (OCEANS '04), vol. 3, pp. 1720-1726, Kobe, Japan, November 2004.

[3] T. Stuart and W. Zhu, "Fast equalization for large lithium ion batteries," IEEE Aerospace and Electronic Systems Magazine, vol. 24, no. 7, pp. 27-31, 2009.

[4] T. A. Stuart and W. Zhu, "A targeted equalizer for lithium ion battery packs," in Proceedings of the 5th IEEE Vehicle Power and Propulsion Conference (VPPC '09), pp. 175-180, IEEE, Dearborn, Mich, USA, September 2009.

[5] T. Hyakudome, H. Yoshida, S. Ishibashi, T. Sawa, and M. Nakamura, "Development of advanced lithium-ion battery for underwater vehicle," in Proceedings of the IEEE Symposium on Underwater Technology (UT) and Workshop on Scientific Use of
Submarine Cables and Related Technologies (SSC '11), pp. 1-4, IEEE, Tokyo, Japan, 2011.

[6] I. Masmitjà Rusinyol, J. González, G. Masmitjà, S. Gomáriz, and J. del-Río-Fernández, "Power system of the Guanay II AUV," Acta IMEKO, vol. 4, no. 1, pp. 35-43, 2015.

[7] I. Shnaps and E. Rimon, "On-line coverage of planar environments by a battery powered autonomous mobile robot," in Algorithmic Foundations of Robotics XI: Selected Contributions of the Eleventh International Workshop on the Algorithmic Foundations of Robotics, vol. 107 of Springer Tracts in Advanced Robotics, pp. 571-589, Springer, Berlin, Germany, 2015.

[8] Y. Wang and Y. Hu, "Battery rack with aluminum injection improvement of battery cabin cooling effect," Northwestern Polytechnical University, vol. 30, no. 3, pp. 428-434, 2012.

[9] Y. Wang and Y. Hu, Affect the Thermal Conductivity of the Battery Holder Auv Battery Inside Cabin Fever and Heat Transfer Processes, vol. 5, Shanghai Jiaotong University, 2012.

[10] Y. Wang, Y. Hu, S. Meng, and P. Wang, "A certain type of underwater vehicle battery cabin thermal process CFD analysis," Defence Technology, vol. 33, no. 4, pp. 476-482, 2012.

[11] B. Ji, X. Song, W. Cao, and V. Pickert, "Active temperature control of Li-ion batteries in electric vehicles," in Proceedings of the IET Hybrid and Electric Vehicles Conference (HEVC '13), pp. 1-5, London, UK, November 2013.

[12] M. Guo and J. Chen, "Passive thermal control structure of the program underwater vehicle lithium battery pack," Mine Warfare and Ship Protection, vol. 18, no. 4, pp. 15r-20r, 2010.

[13] D. Bernardi, E. Pawlikowski, and J. Newman, "A general energy balance for battery systems," Journal of the Electrochemical Society, vol. 132, no. 1, pp. 5-12, 1985.

[14] S. Bhide and T. Shim, "Development of improved Li-ion battery model incorporating thermal and rate factor effects," in Proceedings of the 5th IEEE Vehicle Power and Propulsion Conference (VPPC '09), pp. 544-550, Dearborn, Mich, USA, September 2009.

[15] S. Bhide and T. Shim, "Novel predictive electric Li-ion battery model incorporating thermal and rate factor effects," IEEE Transactions on Vehicular Technology, vol. 60, no. 3, pp. 819-829, 2011.

[16] D. Chen, J. Jiang, Y. Duan, Z. Wang, and F. Wen, "Fluid and thermal analysis of power li-ion battery pack and experimental verification," in Proceedings of the 2013 International Conference on Electrical and Information Technologies for Rail Transportation (EITRT2013)-Volume II, vol. 288 of Lecture Notes in Electrical Engineering, pp. 161-170, Springer, Berlin, Germany, 2014.

[17] N. Javani, I. Dincer, G. F. Naterer, and B. S. Yilbas, "Heat transfer and thermal management with PCMs in a Li-ion battery cell for electric vehicles," International Journal of Heat and Mass Transfer, vol. 72, pp. 690-703, 2014.

[18] Y. Wang, C. Zhang, and Z. Chen, "A method for state-ofcharge estimation of $\mathrm{LiFePO}_{4}$ batteries at dynamic currents and temperatures using particle filter," Journal of Power Sources, vol. 279, pp. 306-311, 2015.

[19] E. Samadani, S. Farhad, W. Scott et al., "Empirical modeling of lithium-ion batteries based on electrochemical impedance spectroscopy tests," Electrochimica Acta, vol. 160, pp. 169-177, 2015. 
[20] C. Heubner, M. Schneider, C. Lämmel, U. Langklotz, and A. Michaelis, "In-operando temperature measurement across the interfaces of a lithium-ion battery cell," Electrochimica Acta, vol. 113, pp. 730-734, 2013.

[21] P. Amiribavandpour, W. Shen, D. Mu, and A. Kapoor, "An improved theoretical electrochemical-thermal modelling of lithium-ion battery packs in electric vehicles," Journal of Power Sources, vol. 284, pp. 328-338, 2015. 


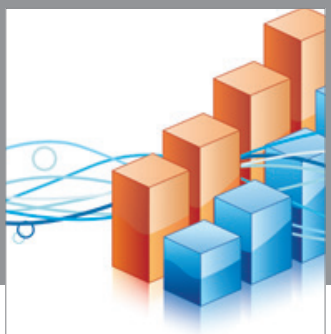

Advances in

Operations Research

vatem alat4

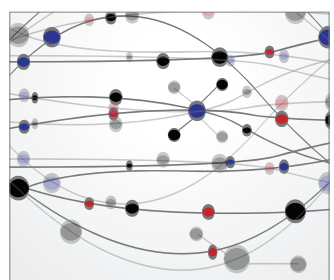

\section{The Scientific} World Journal
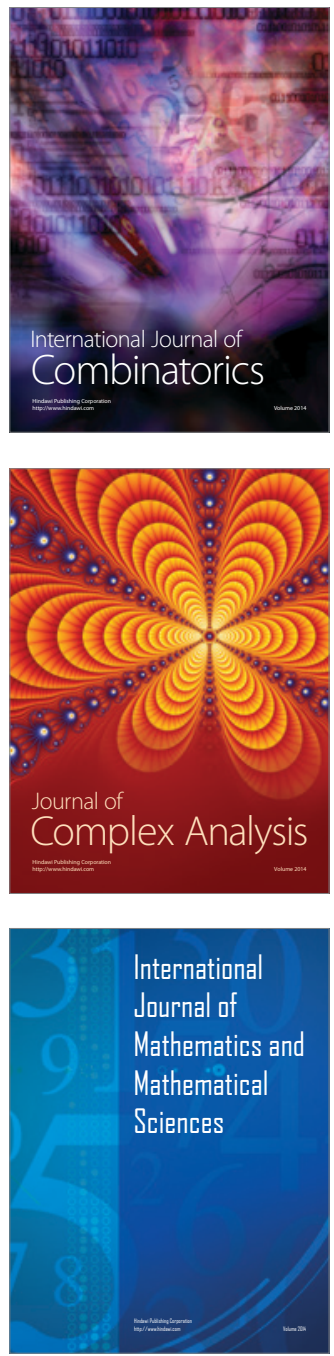
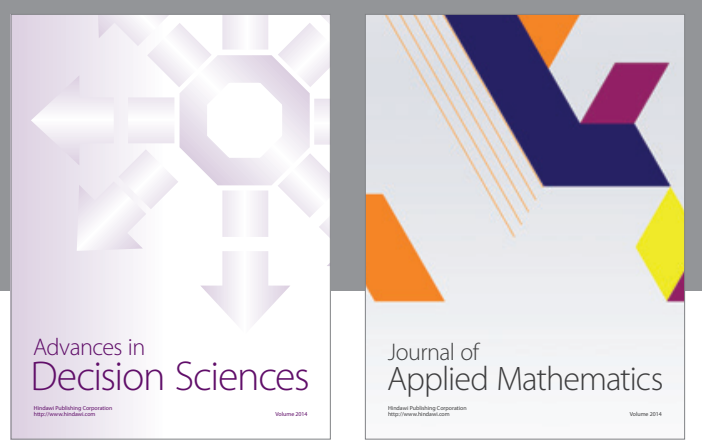

Algebra

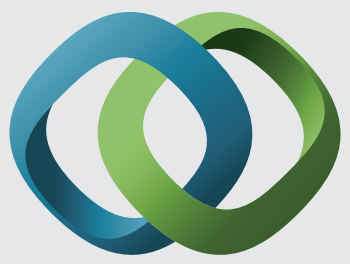

\section{Hindawi}

Submit your manuscripts at

http://www.hindawi.com
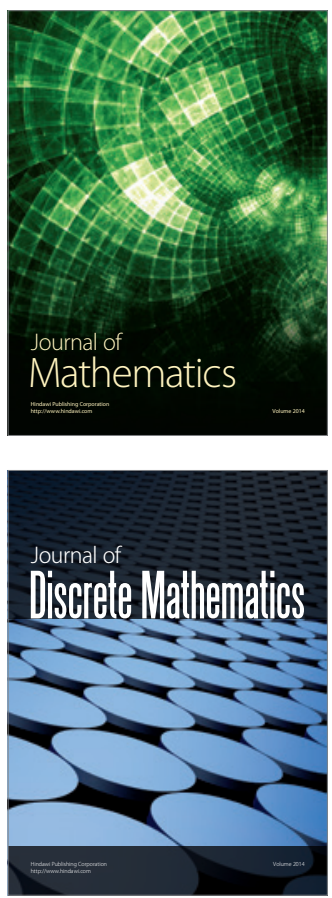

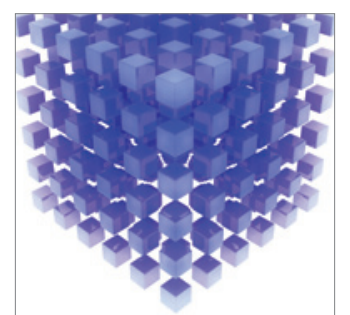

Mathematical Problems in Engineering
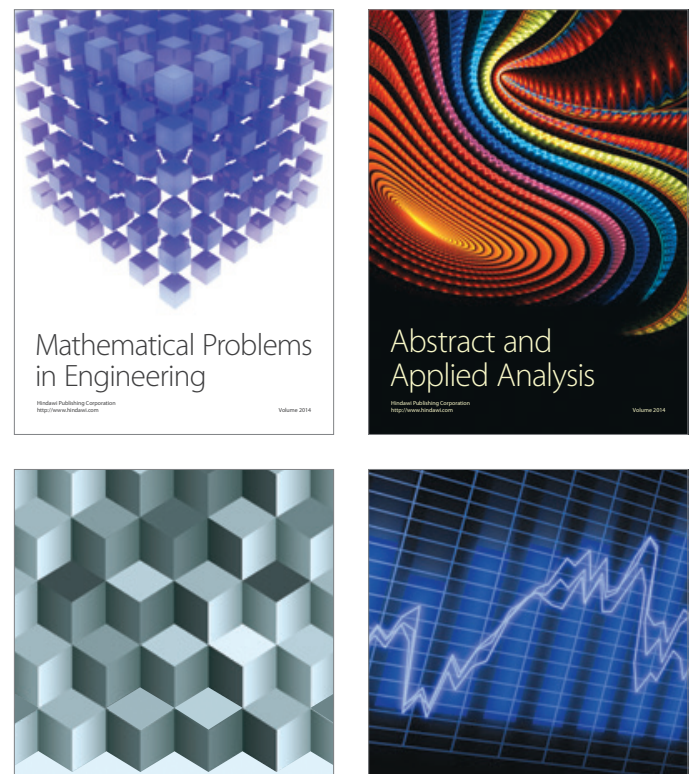

Journal of

Function Spaces

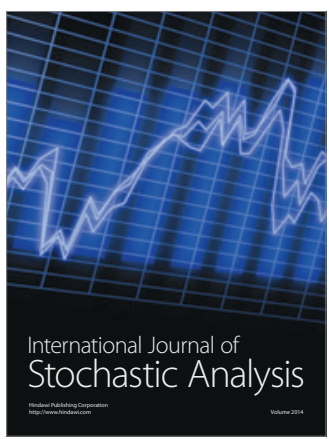

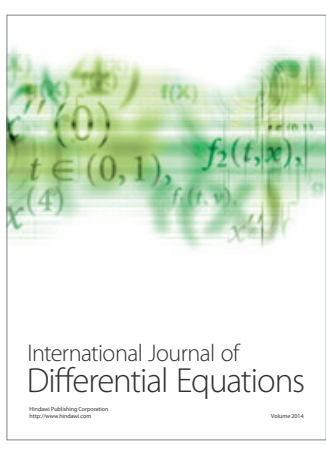
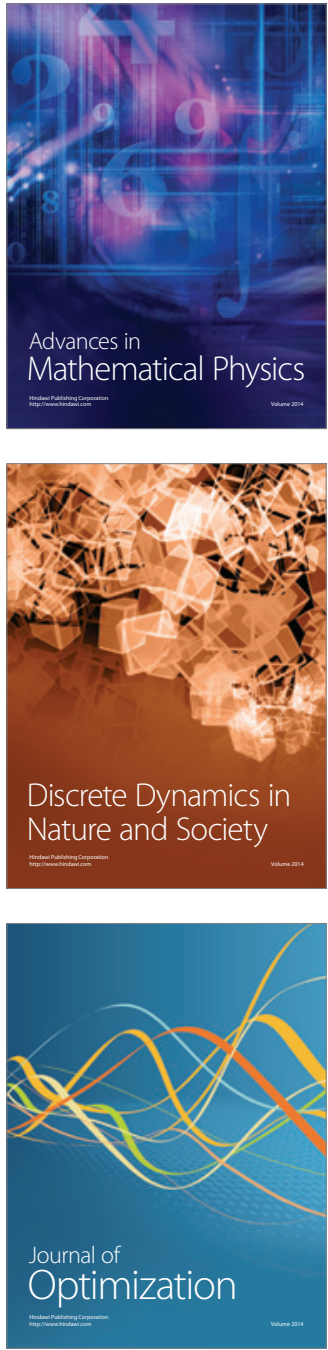